\title{
М.М. Костик
}

Санкт-Петербургский государственный педиатрический медицинский университет, Санкт-Петербург,

Российская Федерация

\section{Нераскрытие конфликта интересов или соблюдение профессиональной этики - что важнее?}

\section{Контактная информация:}

Костик Михаил Михайлович, кандидат медицинских наук, доцент кафедры госпитальной педиатрии СПбГПмУ Адрес: 194100, Санкт-Петербург, ул. Литовская, д. 2, тел.: +7 (812) 416-52-98, e-mail: kost-mikhail@yandex.ru Статья поступила: 07.12.2016 г., принята к печати: 26.12.2016 г.

(Для цитирования: Костик М.М. Нераскрытие конфликта интересов или соблюдение профессиональной этики - что важнее? Вопросы современной педиатрии. 2016; 15 (6): 548. doi: 10.15690/vsp.v15i6.1648)

Понятие "конфликт интересов" на сегодня является важной составляющей публикационного процесса. Отчасти согласен с автором статьи, что раскрытие конфликта интересов "является лучшей мировой практикой, основой честности и добросовестности, одним из гарантов прозрачности их публикации". Я бы добавил, что это, скорее, один из современных («модных") инструментов повышения прозрачности статьи, но вряд ли его можно безусловно считать лучшим и оптимальным. Я не отказываюсь от использования "конфликта интересов" и регулярно, будучи автором, заполняю этот подраздел статьи, однако есть ряд вопросов. Мне кажется, что далеко не всегда полное или частичное раскрытие конфликта интересов является измерителем «прозрачности" публикации, равно как и отрицание конфликта интересов автором не всегда будет искажать содержание статьи и влиять на доверие читателей. Здесь все зависит от человека, его профессиональной порядочности и внутренних этических норм. Я ознакомился с предлагаемой формой для заполнения в журнале, и вот в чем вопрос: автор должен сообщать о всех финансовых взаимоотношениях с фармкомпаниями, фондами, исследовательскими организациями или нет? Может, имеет смысл ввести некий "порог", как делают в зарубежных изданиях? Имеет ли смысл сообщать о финансовых взаимоотношениях, если нет финансовой связи с темой статьи? Имеет ли смысл редакции/издательству интересоваться у авторов наличием связей с государственным управлением, бизнесом? Конечно, когда автор раскрывает конфликт интересов, он частично снимает с себя "подозрения" в ангажированности со стороны фармкомпании, однако, готово ли общество (рядовые читатели) правильно воспринимать эту информацию? Не получится ли, что автор, раскрыв свой конфликт в соответствии с этическими нормами, получит "рикошет" от читателя, что, дескать, "вон сколько компаний ему (ей) платят", "разве можно ему (ей) (им) верить". Необходимо разъяснение этого понятия. Я бы даже предложил редакции провести анкетирование среди авторов, врачей, чтобы узнать, кто и как понимает этот термин, а заодно и узнать отношение к нему среди тех, кто пишет, и тех, кто читает. Думаю, число правильно понимающих авторов, а тем более читателей будет пессимистично, и это может быть одной из причин нежелания разглашать конфликт интересов. Вряд ли редакция сможет повлиять на этот процесс, заполнение раздела "конфликт интересов" лежит целиком на совести авторов. Автор знает о конфликте, но пишет "конфликта нет". Как редакция это проверит, доказательства представить сложно, отказать автору только на основании заявленного отсутствия "конфликта интересов" нельзя. Мне кажется, что в большинстве случаев в нашей стране за нежеланием раскрывать конфликт интересов лежит нежелание вторжения ктолибо в частную жизнь автора: "честно заработанные автором деньги - это его частная жизнь", "почему я должен сообщать о том, где я зарабатываю деньги". Мне кажется, многих авторов беспокоят именно эти вопросы. Автор, не раскрывающий конфликта интересов, может бояться (а зачастую и боится) преследований со стороны, например, своего руководства, налоговых органов, недобросовестных конкурентов. Автор может считать, что его финансовая деятельность послужит поводом для ненужных обсуждений со стороны коллег, начальства, недобросовестных конкурентов. Я лично сталкивался с примерами негативной реакции по отношению к авторам статей. Вопрос - как быть в этой ситуации? Раскрывать конфликт интересов или нет? Какова "цена" раскрытия информации?

Мне кажется, раскрытие "конфликта интересов" должно быть, но оно должно быть добровольным и взвешенным.

Поскольку раскрытие "конфликта интересов" направлено на повышение качества публикационного процесса, то не стоит забывать и о других составляющих этого процесса. Против недобросовестных "уклонистов от раскрытия конфликта интересов" неплохо может работать система слепого рецензирования с привлечением нескольких рецензентов не только из числа состава редколлегий, но и сторонних экспертов, которая избавит от "заказных", "рекламных" статей не менее эффективно, чем раскрытый конфликт интересов. Интересной считаю практику ряда иностранных журналов, в случае публикации статьи указывать фамилии и должности рецензентов, выпустивших статью в печать. Мне кажется, что это повысит степень доверия к статье со стороны читателя в неменьшей степени, чем раскрытый конфликт интересов.

Mikhail M. Kostik

Saint-Petersburg State Pediatric Medical University, Saint-Petersburg, Russian Federation

\section{Non-Disclosure of Conflict of Interest or Adherence to Professional Ethics - What is More Important?}

(For citation: Kostik Mikhail M. Non-Disclosure of Conflict of Interest or Adherence to Professional Ethics - What is More Important? Voprosy sovremennoi pediatrii - Current Pediatrics. 2016; 15 (6): 548. doi: 10.15690/vsp.v15i6.1648) 